\title{
EFFECTIVNESS OF TARGET ANTIMICROBIAL THERAPY OF SEVERE CHRONIC PERIODONTITIS PART I: REDUCTION OF GINGIVAL INFLAMATION AND ACTIVE PERIODONTAL DISEASE SITES
}

\author{
Kotsilkov K., Chr. Popova, V. Dosseva \\ Department of Periodontology, Faculty of Dental Medicine, \\ Medical University - Sofia, Bulgaria
}

\begin{abstract}
:
The correlation between recurrent bleeding on probing and the progression of periodontal destruction is suggested in many studies. One of the main goals of the periodontal treatment is the achievement of good control of the gingival inflammation and the reduction of the active periodontal sites.

Aim: Evaluation of the effectiveness of treatment of severe chronic periodontitis with additional target antibiotic administration in comparison with the therapy with adjunctive antimicrobial combination amoxicillin + metronidazole and conventional mechanical periodontal treatment regarding the achieved control of the gingival inflammation and BoP.

Results: Significant reduction of the gingival bleeding and the BoP is achieved in all groups. In the group with target antibiotic administration the final mean values of the GB (gingival bleeding) and BoP (bleeding on probing) are the lowest and could suggest a low risk for progression of the periodontal disease.
\end{abstract}

Key words: gingival inflammation, periodontitis, periodontal disease progression, risk assessment.

\section{BACKGROUND:}

Periodontal disease is a common inflammatory disease, characterized by loss of the tooth supporting structures, the connective tissue attachment, and alveolar bone. Progressive loss of matrix constituents leading to bone resorption is an essential factor in the loss of tooth supporting tissues. Plaque biofilm and associated host response are the key elements in the pathogenesis of periodontitis $(2,6,7,10,11)$.

It has become quite clear that periodontitis is a multifactorial disease initiated by microorganisms accumulating in the dentogingival area $(3,4)$.

Conventional anti-infectious treatment modalities of periodontal diseases include mechanical removal of microbial plaque and calculus by scaling and root planing (5).
Yet, some cases may need adjunctive chemical treatment $(9,12)$.

Treatment of periodontal diseases by means of chemical adjuncts has addressed the better control of infection using antibiotics and antimicrobials as well as the control of tissue destruction using various host modulators.

The correlation between recurrent bleeding on probing and the progression of periodontal destruction is suggested in many studies. One of the main goals of the periodontal treatment is the achievement of good control of the gingival inflammation and the reduction of the active periodontal sites. Although there is no established acceptable level of prevalence of BoP in the dentition above which a higher risk for disease recurrence has been observed, a BoP prevalence of $25 \%$ has been the cut-off point between patients with maintained periodontal stability for 4 years and patients with recurrent disease in the same time frame. Individuals with low mean BoP percentages $(<10 \%$ of the sites) may be regarded as patients with a low risk for recurrent disease while patients with mean BOP percentages $>25 \%$ should be considered to be at high risk for reinfection. The reduction of GB and BoP prevalence below $25 \%$ in the end of periodontal treatment may be evaluated as a sign of successful periodontal therapy $(1,8)$.

\section{AIM:}

Evaluation of the effectiveness of treatment of severe chronic periodontitis with additional target antibiotic administration in comparison with the therapy with adjunctive antimicrobial combination amoxicillin+ metronidazole and conventional mechanical periodontal treatment regarding the achieved control of the gingival inflammation and BoP.

\section{MATERIALS AND METHODS:}

Patients with active periodontal disease with 3468 affected sites were recruited in this study. Inclusion criteria were at least 20 teeth, 6 sites with $P D>5 \mathrm{~mm}, 2$ sites with $\mathrm{PD}>7 \mathrm{~mm}$ in different dentition quadrants. Exclusion criteria were pregnancy, lactation, systemic antibiotic treatment in 
the previous 3 months. The patients were divided in three groups:

- Test group 1 (TG1) - patents with 834 affected sites - conventional mechanical periodontal therapy and adjunctive broad spectrum systemic antibiotic treatment (Amoxicillin 500mg/Metronidazol 250mg - tid for 10 days.

- Test group 2 (TG2) - patents with 1110 affected sites - conventional mechanical periodontal therapy and adjunctive specific systemic antibiotic administration after microbiological testing for susceptibility.

- Control group (CG) - patients with 1524 affected sites - conventional mechanical periodontal therapy only.

\section{Clinical parameters:}

A full range of periodontal diagnostic measurements were registered before and after treatment. The collected data includes: Hygiene Index (HI), Gingival bleeding index (GBI), Probing depth (PD), Clinical attachment level (CAL), Gingival recession (R), Furcation involvement (F) and Mobility (M) were carried out all patients. The measurements were registered on six points on every tooth (mesiobuccal, buccal, distobuccal, distolingual, lingual, mesiolingual) with Williams's periodontal probe. The alveolar bone loss was registered on panoramic, segment and bite-wing x-rays.

\section{RESULTS:}

Significant reduction of the gingival bleeding and the $\mathrm{BoP}$ is achieved in all groups. In the group with target antibiotic administration the final mean values of the GB (gingival bleeding) and BoP (bleeding on probing) are the lowest and could suggest a low risk for progression of the periodontal disease.

The reduction of the gingival inflammation is one of the major indicators of the successful periodontal treatment. The collected data concerning the gingival status (GBI, BoP) is presented on the following charts. The reduction of the GBI $(46,52 \%$ TG1; 48,87\% TG2, 48,29\% CG) and BoP $(54,14 \% \mathrm{TG} 1 ; 56,83 \% \mathrm{TG} 2,60,28 \% \mathrm{CG})$ is similar in all groups and presents the achieved satisfying control of the gingival inflammation. In TG2 the mean value of the BoP prevalence after treatment is the lowest $(12,46 \%)$ compared with the TG1 $(20,46 \%)$ and CG $(15,67 \%)$ which defines the lowest risk of progression of the periodontal disease for TG2.
Chart 1. Rreduction of the gingival bleeding and the $\mathrm{BoP}$ in correlation with the increase of the free of plaque surfaces in test group 1.

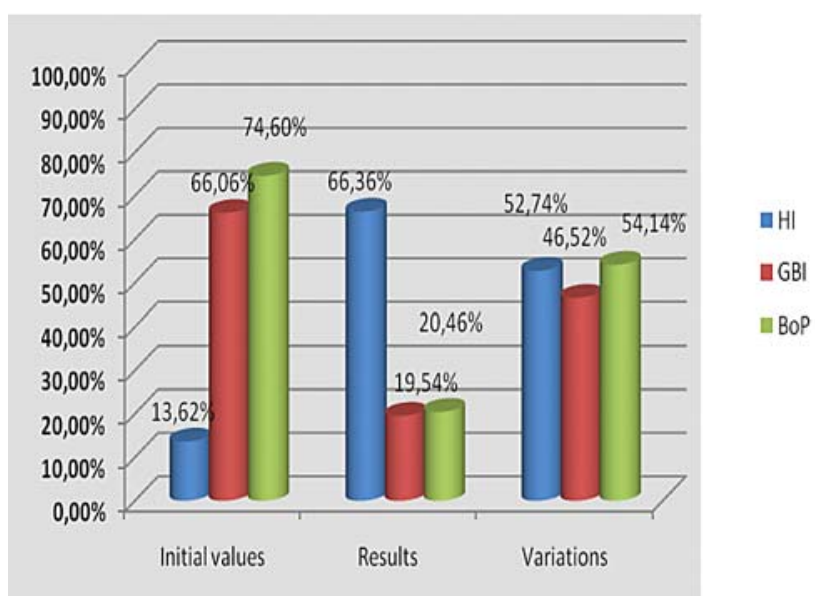

Chart 2. Rreduction of the gingival bleeding and the BoP in correlation with the increase of the free of plaque surfaces in test group 2 .

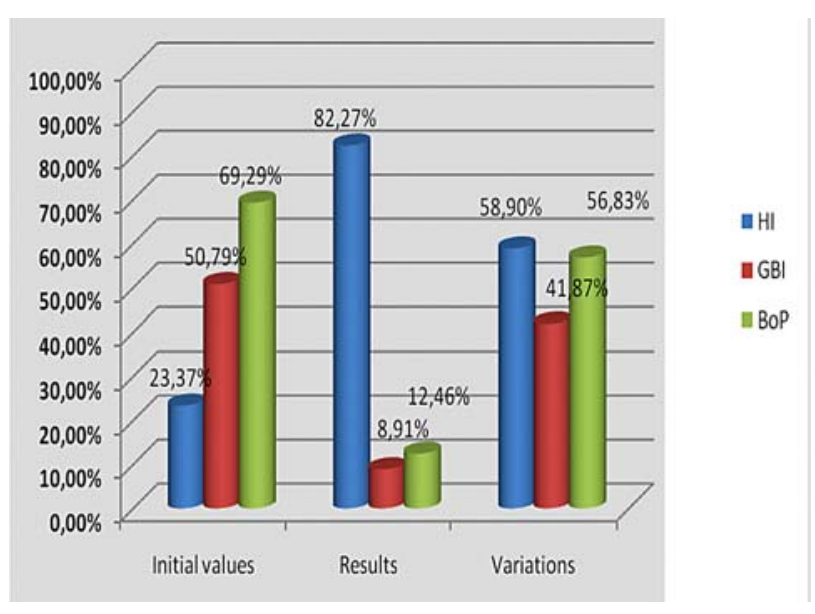


Chart 3. Rreduction of the gingival bleeding and the $\mathrm{BoP}$ in correlation with the increase of the free of plaque surfaces in control group.

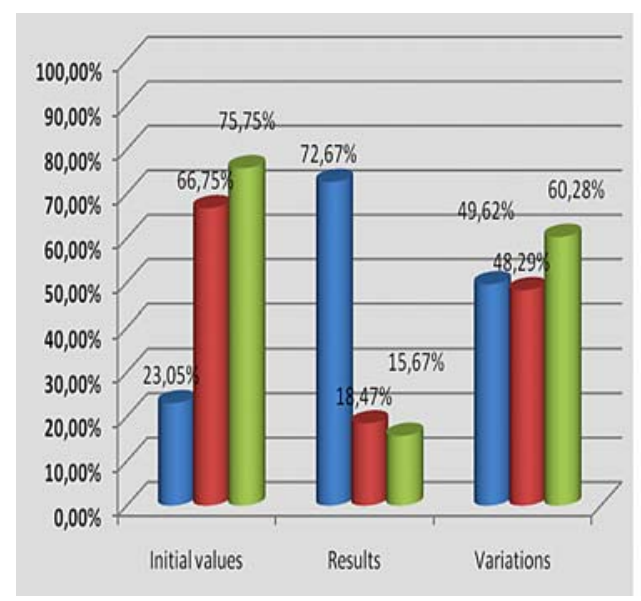

Chart 4. Variations in the gingival bleeding and the BoP in correlation with the improvement of the oral hygiene.

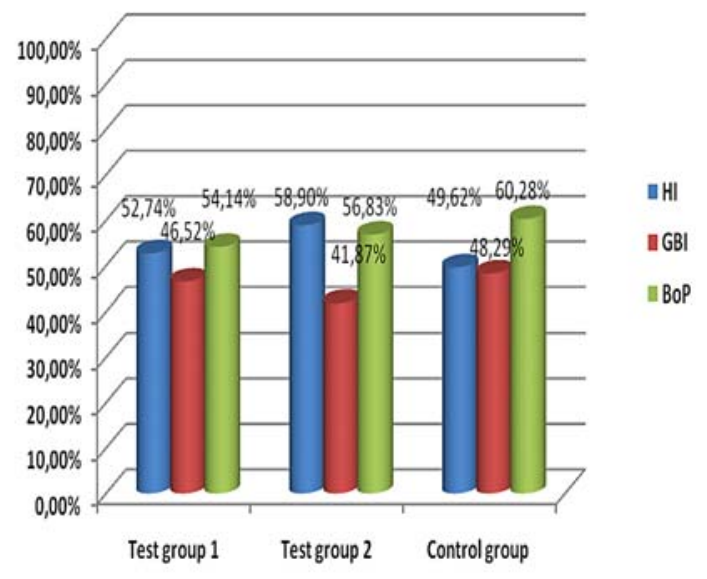

\section{CONCLUSION:}

Significant reduction of the gingival bleeding and the BoP is achieved in all groups. In the group with target antibiotic administration the final mean values of the GB (gingival bleeding) and BoP (bleeding on probing) are the lowest and could suggest a low risk for progression of the periodontal disease.

\section{REFERENCES:}

1. Armitage GC. The complete periodontal examination. Periodontol 2000, 2004; 34: 22-33.

2. Dahlen G. Role of suspected periodontopathogens in microbiological monitoring in periodontitis. Adv Dent Res 1993; 7(2): 163-174.

3. Djemileva, T. Periodontal diseases. Azer Sofia, 1999, 367p.

4. Djemileva-Konova, T. Clinical and experimental data for the influence of the dental plaque upon gingival tissue. Diss., Sofia, Faculty of Stomatology, 1976, 250p.

5. Haffajee AD., Cugini MA., Dibart S., Smith C., Kent RL., Socransky SS. The effect of SRP on the clinical and microbiological parameters of periodontal disease. J Clin Periodontol 1997; 24: 324334.

6. Haffajee AD., Socransky SS. Microbial etiological agents of destructive periodontal diseases. Periodontol 2000, 1994 Jun; 5: 78-111.

7. Nishihara T., Koseki T. Microbial etiology of periodontitis. Periodontology 2000, 2004; 36: 14-26.

8. Persson GR. Site-based versus subject-based periodontal diagnosis. Periodontology 2000, 2005; 39: 145-163.

9. Popova Chr. Control and prevention of gingival inflammation by chemical inhibition of dental plaque. Контрол и превенция на гингивалното възпаление чрез химическа инхибиция на зъбната плака. Diss., Sofia, Faculty of Stomatology, 1998, 187p.

10. Socransky SS., Haffajee AD. Periodontal microbial ecology. Periodontology 2000, 2005; 38: 135-187.

11. Socransky SS., Haffajee AD., Cugini MA., Smith C., Kent RL. Microbial complexes in subgingival plaque. J Clin Periodontol 1998; 25(2):134-144.

12. Winkel EG, van Winkelhoff AJ, Timmerman MF, Van der Velden U, van der Weijden GA. Amoxicillin plus metronidazole in the treatment of adult periodontitis patients. A double-blind placebo-controlled study. J Clin Periodontol 2001;28:296-305. 